\title{
CLINICAL AND HISTOPATHOLOGICAL PROFILE OF PATIENT WITH SOLITARY THYROID NODULE IN TERTIARY CARE HOSPITAL IN SOUTH INDIA
}

\author{
S. Mohamed Musthafa' ${ }^{1}$, D. S. A. Mahadevan², Rajesh Daniel ${ }^{3}$, Rahul Rai ${ }^{4}$, D. Pari Vallal ${ }^{5}$, M. Lokesh Reddy ${ }^{6}$, R. Abhinav Bharadwaj $^{7}$
}

${ }_{1}^{1}$ Professor, Department of General Surgery, SRM Medical College and Hospital and Research Centre.

${ }^{2}$ Professor, Department of General Surgery, SRM Medical College and Hospital and Research Centre.

${ }^{3}$ Assistant Professor, Department of General Surgery, SRM Medical College and Hospital and Research Centre.

${ }^{4}$ Former Postgraduate Student, Department of General Surgery, SRM Medical College and Hospital and Research Centre.

5Postgraduate Student, Department of General Surgery, SRM Medical College and Hospital and Research Centre.

${ }^{6}$ Postgraduate Student, Department of General Surgery, SRM Medical College and Hospital and Research Centre.

7Postgraduate Student, Department of General Surgery, SRM Medical College and Hospital and Research Centre.

ABSTRACT
BACKGROUND
Incidence of malignancy in a solitary thyroid nodule is higher than in multinodular goitre. The prevalence of nodules in the general
population is around 8\% with greater predisposition in females. This study was undertaken to study the functional status of
solitary nodules and to analyse the types of malignancy occurring in solitary nodules.

\section{MATERIALS AND METHODS}

This cross-sectional study was done among patients who presented with anterior neck swelling and diagnosed as Solitary Thyroid Nodule in SRM Medical College Hospital and Research Centre, SRM Nagar, Kattankulathur, Kancheepuram Dist., Tamilnadu. Clinical, laboratory and histopathological evaluation of patients was done for confirmation of findings.

\section{RESULTS}

Total of 50 cases of Solitary Thyroid Nodule were studied. The age of the patients ranged from 22 years to 66 years (Mean age= 38.44 years). Solitary Nodule of Thyroid was more common in females. The distribution of nodule either on right or left side was almost equal. The size of the nodule varied from $2 \mathrm{~cm}$ to $7 \mathrm{~cm}$. Most patients (38) presented with a size between 2 to $4 \mathrm{~cm}$. Based on histopathological confirmation 4 out of the 50 patients were found to have malignancy, which comprised $8 \%$ of the study population. Follicular adenoma was present in $24 \%$ of the patients. Adenomatous goitre was present in $62 \%$ of the patients and simple cysts in $2 \%$ of the patients.

\section{CONCLUSION}

This study shows that Solitary Nodule of Thyroid is more common in females and in 3rd to 5th decades of their age. Incidence of Malignancy in Solitary Nodule of Thyroid is 8\%. Histopathology reports proved that Papillary Carcinoma is most common malignancy in patients with solitary nodule.

\section{KEYWORDS}

Solitary Thyroid Nodule, Incidence of Malignancy, Papillary Carcinoma.

HOW TO CITE THIS ARTICLE: Musthafa SM, Mahadevan DSA, Daniel R, et al. Clinical and histopathological profile of patient with solitary thyroid nodule in tertiary care hospital in South India. J. Evolution Med. Dent. Sci. 2017;6(89):6196-6199, D0I: $10.14260 /$ jemds/2017/1347

\section{BACKGROUND}

Diseases of thyroid gland are the most common among endocrine glands. One of the common presentations of thyroid diseases is nodular thyroid swelling. Thyroid nodules are found in $4 \%$ - $8 \%$ of adults by palpation and in $13 \%-67 \%$ when ultrasound detection is used. ${ }^{1}$ The usual presentation of a thyroid nodule is asymptomatic and is either discovered by the patient or clinician. Nodules of at least $0.5 \mathrm{~cm}$ to $1 \mathrm{~cm}$ can be detected usually by palpation, although estimates of nodule size varies from physician to physician. ${ }^{2}$ Thyroid nodules develop at the edge of thyroid glands and present a

'Financial or Other Competing Interest': None.

Submission 24-10-2017, Peer Review 05-11-2017,

Acceptance 07-11-2017, Published 13-11-2017.

Corresponding Author:

Dr. D. S. A. Mahadevan,

Department of General Surgery,

SRM Medical College Hospital,

Potheri.

E-mail: dsamahadevan52@gmail.com

DOI: $10.14260 /$ jemds $/ 2017 / 1347$

\section{(c) (i) $\odot$}

challenge in their diagnosis, evaluation, treatment and management. FNAC is the most crucial step in the evaluation of a thyroid nodule and is the procedure of choice in the workup of thyroid nodule. ${ }^{3}$

A Solitary Nodule is defined as "a palpable single clinically detected nodule in the thyroid gland that is otherwise normal." 4 A thyroid nodule larger than $1 \mathrm{~cm}$ in diameter is usually palpable. The detection of a nodule by palpation depends on its location within the thyroid gland, on the structure of the patient's neck and on the experience of the examiner. Majority of thyroid nodules are benign. In 1975 Gogas JG and Skalheas GD in their study on 1300 thyroidectomies, of which 70 had carcinoma. ${ }^{5}$ The incidence of malignancy in solitary nodule was $9.7 \%$. Overall incidence of malignancy in solitary thyroid nodule ranges from $10 \%$ $30 \% .^{6}$ Papillary thyroid cancer (PTC) is identified in $87 \%$ of solid nodules, $7 \%$ of mixed composition nodules and $6 \%$ of predominantly cystic nodules. ${ }^{3}$

Lymphomas and metastatic tumour can also occur in solitary thyroid nodules, but less frequently. Thyroid cancer 
has a favourable prognosis and accounts for less than $0.5 \%$ of cancer deaths. ${ }^{7}$ The recent data suggests that the incidence of thyroid malignancy is increasing over the years.8,9 The occurrence of malignancy is more in solitary thyroid nodules compared to multinodular goitre. ${ }^{10,11}$ This increase in incidence is due to identification through the use of ultrasound examinations and the emphasis on early detection of cancer over the past three decades. ${ }^{12}$

The occurrence of solitary thyroid nodule is a common entity. Clinically, palpable nodules are reported in $8 \%$ of the adult population. With the use of imaging techniques, particularly ultrasound, the chance of detection of thyroid nodules has increased many folds. ${ }^{13,14}$ Solitary thyroid are seen approximately in $4 \%$ to $7 \%$ of the population in iodine sufficient areas with a markedly increased incidence in iodine-deficient regions. ${ }^{15}$ The prevalence of palpable thyroid nodule in South India is about $12.2 \% .{ }^{16}$

Thyroid nodules occur at all ages. The reported age ranges from 15 - 69 years with maximum incidence in 30 - 40 years. Solitary nodule is rare in children, the incidence of carcinoma in such a nodule under 25 years of age is about $50 \%$ and $75 \%$ in patients under 15 years. Solitary nodule found in thyroid of patients less than 20 years and greater than 60 years carries far greater risk of being malignant.

Solitary nodule of thyroid can arise from diverse causes. The common causes of solitary thyroid nodules are adenomatous goitre, neoplasms and chronic thyroiditis. The aetiology of the nodule depends upon the population under study, sex, age of patient and prior history of exposure to ionising radiation. Factors such as parity, early menopause, contraceptive use and late age at first birth in female population have been reported to have increased risk of thyroid carcinoma, but the data has been inconsistent. The thyroid nodule is more likely to be a cancer in men than in women and in young (under 20 years) and older (over 60 years) patients rather than others.

Thyroid ultrasound features associated with malignancy in thyroid nodules are microcalcifications, hypoechogenicity, irregular margins or absent halo sign, solid areas, intranodular vascularisation. ${ }^{17}$ Thyroid ultrasonography is the recognised "Gold standard" for an accurate and reliable assessment of gland volume and thyroid nodules. ${ }^{18}$ FNAC also plays a crucial role in diagnosis of type of Solitary thyroid nodule.

Since there is a high risk of malignancy in STN than in multiple nodules, STN have to be treated with high degree of suspicion and plan treatment in a systematic manner. The optimal management of the thyroid nodule continues to be a source of controversy and the operative intervention recommended by most surgeons is not always considered divine by some physicians advocating either observation or suppression. ${ }^{19}$ This study was undertaken to study the incidence of Euthyroid, Hyper and Hypothyroid states in solitary nodules with proven malignancy and to analyse the types of malignancy occurring in solitary nodules and its surgical management. The aim of the study is also to determine the incidence of solitary thyroid nodule in relation to age and sex.

\section{MATERIALS AND METHODS}

This cross-sectional study was done among patients who were admitted in SRM Medical College Hospital and Research
Centre, SRM Nagar, Kattankulathur, Kancheepuram Dist., Tamilnadu. The duration of study was eighteen months. As per inclusion criteria, patients who presented with anterior neck swelling and diagnosed as solitary thyroid nodule and patients with recurrent nodule were included in the study. Patients below 16 years of age and patients diagnosed with multinodular goitre were excluded from the study. Total sample size for this study was 50 patients. Thorough history and clinical examination including cervical lymph nodes was done. Laboratory evaluation was done for assessing the TSH, free T3, free T4 and Thyroglobulin Assay of patients. For all patients ultrasonogram examination was done to evaluate the size, shape, composition and calcification of thyroid nodule. FNAC was also done for the patients. All the patients were managed surgically and diagnosis was confirmed from the histopathological examination reports.

\section{RESULTS}

Total of 50 cases of solitary thyroid nodule were studied. The age of the patients ranged from 22 years to 66 years with peaks beginning in $3 \mathrm{rd}$ to 5 th decades. Mean age of presentation is 38.44 years; 3 rd to 5 th decades constitute $>70 \%$ of the cases studied. Solitary nodule of thyroid are more common in females. Out of 50 cases studied, 40 were females and 10 were males. The ratio was observed to be 1:4 (Males: Females).

\begin{tabular}{|c|c|c|}
\hline Variable & Frequency & Percentage \\
\hline \multicolumn{3}{|c|}{ Age in Years } \\
\hline $20-29$ & 16 & 32 \\
\hline $30-39$ & 16 & 32 \\
\hline $40-49$ & 7 & 14 \\
\hline $50-59$ & 6 & 12 \\
\hline $60-69$ & 5 & 10 \\
\hline Sex & 10 & 20 \\
\hline Males & 40 & 80 \\
\hline Females & Table 1. Age and Sex Distribution of Study Participants
\end{tabular}

\section{Site of the Nodule}

Out of 50 cases studied, 26 cases presented with nodules in the right lobe and the remainder in the left lobe. One patient among left-sided solitary nodule had undergone right hemithyroidectomy ten years prior and presented with a recurrent nodule on the left side.

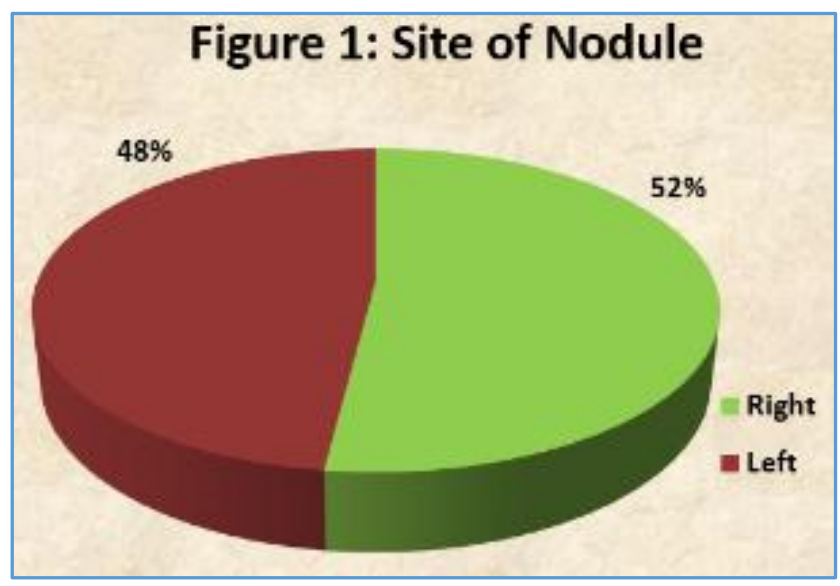




\section{Size of the Nodule}

In this study, on clinical examination, size of the nodule in its largest dimension varied from $2 \mathrm{~cm}$ to $7 \mathrm{~cm}$. Most patients (38) presented with a size between 2 and $4 \mathrm{~cm}$. For 9 patients, size was between 4 and $5 \mathrm{~cm}, 2$ patients between 5 and $7 \mathrm{~cm}$ and in one patient the size was less than $2 \mathrm{~cm}$. Out of the 50 cases, all of the cases presented to the General Surgery OPD in Euthyroid state. Amongst these, two patients were on treatment for Hypothyroidism (Thyroxine) prior to admission. Both of these were free from malignancy.

\section{FNAC Reports}

FNAC reports of patients revealed Benign in 64\%, Follicular neoplasm in $24 \%$, Suspicious in $4 \%$, Malignancy in $2 \%$ and Lymphocytic thyroiditis in $4 \%$ of patients.

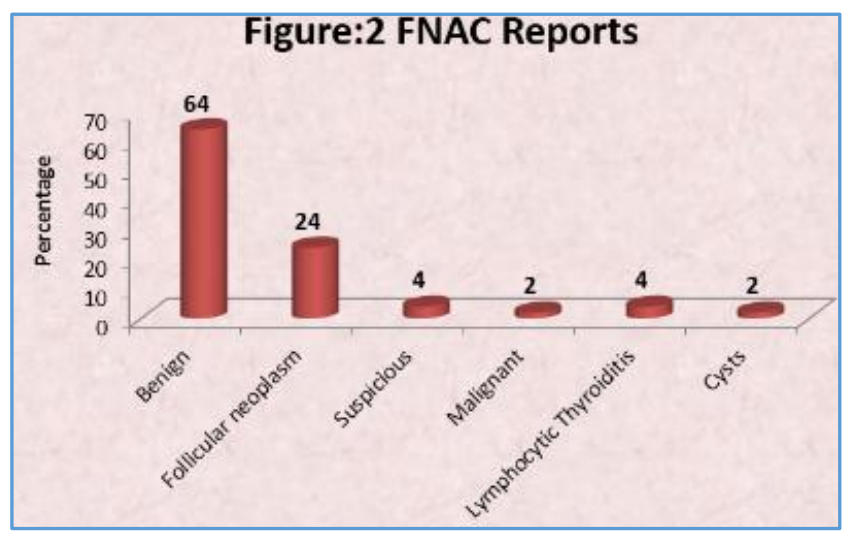

\section{Incidence of Malignancy}

4 out of the 50 patients were found to have malignancy, which comprised $8 \%$ of the study population. Two of them had papillary carcinoma and two of them had anaplastic carcinoma. Of the four malignant cases, two were correctly identified by FNAC and the remaining two cases were reported as suspicious by FNAC. One out of the four malignancies observed was from the Kancheepuram district (14 out of 50 patients were from the district). There was no observed obvious increase in the incidence of malignancy around the Kalpakkam nuclear plant.

Follicular adenoma was present in $24 \%$ of the patients. Adenomatous goitre was present in $62 \%$ of the patients and simple cysts in $2 \%$ of the patients.

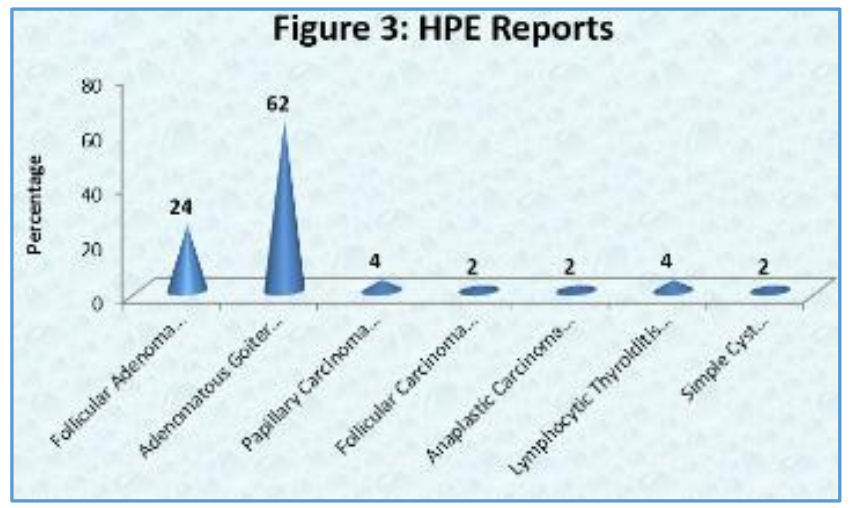

\section{DISCUSSION}

The present study is a cross-sectional analysis of 50 cases of Solitary Nodule of Thyroid admitted in SRM MCH and RC, Kattankulathur. The findings of this study were compared to those done previously. In this study, the mean age of incidence (38.44 yrs.) is similar to the previously done studies with the majority of patients being between the 3rd and 5th decades. Das DK (1999) ${ }^{20}$ reported mean age as 35 yrs., Talipoor M (2005) ${ }^{21}$ reported mean age as 38.6 yrs. and Khurshid Anwar (2012) ${ }^{22}$ reported mean age as 37 yrs. Naz Aktar in his study on solitary thyroid nodule reported that most of the patients are between 21 - 40 years of age, i.e. $64.5 \% .^{23}$

Already literatures have proven that thyroid nodules can be found in up to $90 \%$ of women over the age of 60 years. They are $3-4$ times more frequent in women than men. ${ }^{24}$ In the present study, the ratio of Male: Female was observed as 1:4 and is similar to that observed by Gupta C in 2001 (1:5). ${ }^{25}$ Das DK (1999) ${ }^{20}$ reported 1: 5.3 as sex ratio of solitary thyroid nodule and Dorairajan $(1996)^{4}$ reported sex ratio of patients presenting with solitary thyroid nodule as $1: 9$. The occurrence of thyroid nodule formation is very high in females as compared with male counterparts due to fluctuations in the demands of the hormonal requirement in their life cycle (puberty, menstrual cycles, pregnancy and menopause). ${ }^{26}$

Fine Needle Aspiration Cytology is an important investigating tool in the evaluation of solitary nodule of thyroid. It is recommended that every patient with a palpable thyroid nodule should undergo an FNAC. All 50 cases were subjected to FNAC during the course of evaluation. FNAC reports are mainly categorised into 6 entities. Benign, follicular neoplasm, suspicious (of malignancy), malignant, lymphocytic thyroiditis and cysts. In the present study, FNAC reports of patients revealed Benign in 64\%, Follicular neoplasm in $24 \%$, Suspicious in $4 \%$, Malignancy in $2 \%$ and Lymphocytic thyroiditis in $4 \%$ of patients. Out of four malignancies that were confirmed by histopathology, two cases were correctly reported by FNAC and the remaining two cases were reported as suspicious. A study done by Jena et al $^{11}$ reported that fine-needle aspiration cytology done before the surgery on 146 patients, the findings were nodular goitre in $62(42.5 \%)$, follicular neoplasm in 55 (37.7\%), papillary carcinoma in $25(17.1 \%)$, Hashimoto thyroiditis in two $(1.4 \%)$, toxic nodule in one $(0.7 \%)$ and medullary carcinoma in one $(0.7 \%)$ patient.

The actual incidence of malignancy was found to be at $8 \%$ in the present study based on histopathological reports. Fenn et al $(1980)^{27}$ reported incidence of $12 \%$, Bhansali SK $(1982)^{28}$ reported $9 \%$ as incidence, Kapur et al (1982) 29 and Rehman AU (2009) ${ }^{30}$ reported $11 \%$ as incidence of malignancy among patients with solitary nodule (Table 2). Naz Aktar in his study reported a higher prevalence of malignancy $(15.3 \%)$ in solitary nodule. ${ }^{23}$

\begin{tabular}{|c|c|}
\hline Study & Percentage \\
\hline Fenn et al(1980) & $12 \%$ \\
\hline Bhansali SK (1982) & $9.0 \%$ \\
\hline Kapur et al (1982) & $11.0 \%$ \\
\hline Rehman AU (2009) & $11.4 \%$ \\
\hline Present Study & $8.0 \%$ \\
\hline \multicolumn{2}{|c|}{$\begin{array}{c}\text { Table 2. Incidence of Carcinoma in Thyroid Nodule from } \\
\text { Various Study Reports }\end{array}$} \\
\hline
\end{tabular}

One out of the four cases of malignancy observed was from the Kancheepuram district out of a total of 14 cases. Overall, we see that the findings observed in this study are 
more or less similar to the ones observed by other researchers in various parts of the country.

\section{CONCLUSION}

This study shows that Solitary Nodule of Thyroid is more common in females. Solitary Nodule of Thyroid is more common in the 3rd to 5th decades. Most of the patients present with swelling alone. Most of the patients are in Euthyroid state with a few in Hypothyroid. Incidence of Malignancy in Solitary Nodule of Thyroid is $8 \%$. Histopathology reports proved that Papillary Carcinoma and anaplastic carcinoma are in equal proportion among patients with solitary nodule. This study emphasises the need for early diagnosis and treatment of solitary thyroid nodule.

\section{REFERENCES}

[1] Wang C, Crapol LM. The epidemiology of thyroid disease and implications for screening. Endocrinol Metab Clin North Am 1997;26(1):189-218.

[2] Burch HB. Evaluation and management of the solitary nodule. Endocrinol Metab Clin North Am 1995;24(4):663-94.

[3] Wang TS, Cheng DW, Udelsman R. Contemporary imaging for thyroid cancer. Surg Oncol Clin N Am 2007;16(2):431-45.

[4] Dorairajan N, Jayashree N. Solitary nodule of the thyroid and role of fine needle aspiration cytology in diagnosis. J Indian Med Assoc 1996;94(2):50-2.

[5] Anitha S, Ravimohan TR. A study of incidence of malignancy in solitary nodule of thyroid. International Journal of Contemporary Medical Research 2016;3(4):993-5.

[6] Harrison BJ, Maddox PR, Smith DM. Disorders of thyroid gland. In: Cuschieri A, Steele RJC, Moossa AR. (eds). Essential surgical practice. $4^{\text {th }}$ edn. London: Arnold, 2002:95-110.

[7] Nadgouda VG. Approach to a patient with "solitary thyroid nodule" (STN). Medicine Update 2011:185-90.

[8] Yeung MJ, Serpell JW. Management of the solitary thyroid nodule. Oncologist 2008;13(2):105-12.

[9] Gupta M, Gupta S, Gupta VB. Correlation of fine needle aspiration cytology with histopathology in the diagnosis of solitary thyroid nodule. J Thyroid Res 2010;2010:379051.

[10] Iqbal M, Mehmood Z, Rasul S, et al. Carcinoma thyroid in multi and uninodular goiter. J Coll Physicians Surg Pak 2010;20(5):310-2.

[11] Jena A, Patnayak R, Prakash J, et al. Malignancy in solitary thyroid nodule: a clinicoradiopathological evaluation. Indian J Endocrinol Metab 2015;19(4):498-503.

[12] Capezzone M, Morabito E, Bellitti P, et al. Increasing incidence of thyroid cancer in Basilicata: an Italian study. J Endocrinol Invest 2007;30(6):507-12.

[13] Unnikrishnan AG, Kalra S, Baruah M, et al. Endocrine society of India management guidelines for patients with thyroid nodules: a position statement. Indian J Endocrinol Metab 2011;15(1):2-8.
[14] Davies L, Welch HG. Increasing incidence of thyroid cancer in the United States, 1973-2002. JAMA 2006;295(18):2164-7.

[15] Popli MB, Rastogi A, Bhalla PJS, et al. Utility of grayscale ultrasound to differentiate benign from malignant thyroid nodules. Indian J Radiol Imaging 2012;22(1):63-8.

[16] Menon UV, Sundaram KR, Unnikrishnan AG, et al. High prevalence of undetected thyroid disorders in an iodine sufficient adult south Indian population. J Indian Med Assoc 2009;107(2):72-7.

[17] Rago T, Vitti P. Role of thyroid ultrasound in the diagnostic evaluation of thyroid nodules. Best Pract Res Clin Endocrinol Metab 2008;22(6):913-28.

[18] Gallo M, Pesenti M, Valcavi R. Ultrasound thyroid nodule measurements: the "gold standard" and its limitations in clinical decision making. Endocr Pract 2003;9(3):194-9.

[19] Belfiore A, La Rosa GL. Fine needle aspiration biopsy of the thyroid. Endocrinol Metab Clin 2001;30(2):361400.

[20] Das DK, Khanna CM, Tripathi RP, et al. Solitary nodular goiter. Review of cytomorphologic features in 441 cases. Acta Cytol 1999;43(4):563-74.

[21] Talepoor M, Karbankhsh M, Mirzali FA. Management of solitary thyroid nodules: the dilemma of multinodular goiter as false-positive cases. Medicine On-Line; 2005. January. Available from: http://www.priory.com/ med/thyroidnodule.htm. [Last accessed on 2017 July 03].

[22] Anwar K, Din G, Zada B, et al. The frequency of malignancy in a nodular goiter-a single center study. J Postgrad Med Inst 2012;26(1):96-101.

[23] Akhtar N, Buzdar MU, Khan MA. Frequency of malignancy in solitary thyroid nodule. PJMHS 2015;9(3):983-5.

[24] Lansford CD, Teknos TN. Evaluation of the thyroid nodule. Cancer Control 2006;13:89-98.

[25] Gupta C, Sharma VK, Agarwal AC, et al. Fine needle aspiration cytology of solitary nodule of thyroid and its histopathological correlation. Journal of Cytology 2001;18(3):151-6.

[26] Fernando JR, Raj SEK, Kumar AM, et al. Clinical study of incidence of malignancy in solitary nodule of thyroid. International Journal of Scientific Study 2017;5(4):232-6.

[27] Fenn AS. Solitary nodule of thyroid gland. Ind J Surg 1980;42:175-1.

[28] Bhansali SK. Solitary nodule in thyroid gland. Experience with 600 cases. Ind J Surg 1982;44:547-61.

[29] Kapur. Sarin solitary thyroid nodule. Ind J of Surg 1982;44:174-9.

[30] Rehman AU, Lodhi S, Anwar M. Histopathological evaluation of 432 cases of goiter. Annals 2009;15:54-6. 